Article

\title{
Quantifying the Effect of Different Urban Planning Strategies on Heat Stress for Current and Future Climates in the Agglomeration of The Hague (The Netherlands)
}

\author{
Sytse Koopmans ${ }^{1, *(1)}$, Reinder Ronda ${ }^{2}$, Gert-Jan Steeneveld ${ }^{1}{ }^{(\mathbb{C}}$, Albert A.M. Holtslag ${ }^{1}$ (D) \\ and Albert M.G. Klein Tank ${ }^{1,2}$ \\ 1 Meteorology and Air Quality Section, Wageningen University, P.O. Box 47, 6700AA Wageningen, \\ The Netherlands; gert-jan.steeneveld@wur.nl (G.-J.S.); bert.holtslag@wur.nl (A.A.M.H.); \\ albert.kleintank@wur.nl (A.M.G.K.T.) \\ 2 Royal Netherlands Meteorological Institute, P.O. Box 201, 37371 GA De Bilt, The Netherlands; \\ reinder.ronda@knmi.nl \\ * Correspondence: sytse.koopmans@wur.nl
}

Received: 29 May 2018; Accepted: 29 August 2018; Published: 13 September 2018

\begin{abstract}
In the Netherlands, there will be an urgent need for additional housing by the year 2040, which mainly has to be realized within the existing built environment rather than in the spatial extension of cities. In this data-driven study, we investigated the effects of different urban planning strategies on heat stress for the current climate and future climate scenarios (year 2050) for the urban agglomeration of The Hague. Heat stress is here expressed as the number of days exceeding minimum temperatures of $20^{\circ} \mathrm{C}$ in a year. Thereto, we applied a diagnostic equation to determine the daily maximum urban heat island based on routine meteorological observations and straightforward urban morphological properties including the sky-view factor and the vegetation fraction. Moreover, we utilized the Royal Netherlands Meteorological Institute's (KNMI) climate scenarios to transform present-day meteorological hourly time series into the future time series. The urban planning strategies differ in replacing low- and mid-rise buildings with high-rise buildings (which reduces the sky-view factor), and constructing buildings on green areas (which reduces the vegetation fraction). We found that, in most cases, the vegetation fraction is a more critical parameter than the sky-view factor to minimize the extra heat stress incurred when densifying the neighbourhood. This means that an urban planning strategy consisting of high-rise buildings and preserved green areas is often the best solution. Still, climate change will have a larger impact on heat stress for the year 2050 than the imposed urban densification.
\end{abstract}

Keywords: urban heat island; urban planning; heat resilience; climate scenarios

\section{Introduction}

Climate change is expected to affect society substantially in terms of increased temperatures and precipitation, as well as more frequent weather extremes [1,2]. Sophisticated climate-change projections were carried out for many countries including the Netherlands. However, these projections mostly focus on rural areas, while policy makers are also interested in how they can make future cities more heat-resilient. The Netherlands has the challenge of realizing one million new houses by the year 2040, which mainly need to be created within the existing built environment. This study aims to clarify how climate change evolves in Dutch cities, and which urban morphological factors need to be modified in order to reduce heat stress. 
Temperatures in cities are typically significantly higher for most of the day compared to their rural surroundings [3]. The heat stress due to these higher temperatures has a significant impact on health $[4,5]$. These elevated urban temperatures are known as the urban heat island (UHI), which is defined as the difference in $2 \mathrm{~m}$ of air temperature difference between a city and the surrounding countryside. Many factors contribute to a warmer urban environment. In general, the radiation balance of a city is altered due to its complex canyon structure, which results in a relatively small albedo, and thus, a large energy gain for the urban surface [6]. Furthermore, the energy balance of urban areas is different from rural areas due to the lower sky-view factor [3,7], enhanced impervious surfaces (initiating a higher sensible heat flux at the expense of the latent heat flux), and anthropogenic heat release [8]. Because of the relatively large heat conductivity and thermal capacity of the urban fabric, cities can store more heat during the daytime than rural environments. This energy is released after sunset creating the largest UHI in the evening or onset of the night. The elevated temperatures in urban areas affect human health and are a significant contributor to the excess mortality observed during heat waves $[4,5]$. High night-time temperatures have adverse effects on human health by preventing an adequate recovery from daytime heat and by inducing sleep deprivation [9]. The best known examples for western Europe were the high number of excess deaths in France during the heat waves of 2003 and $2006[10,11]$. In the Netherlands, the number of excess deaths was estimated to be between 1400 and 2200 in the summer of 2003 [12].

The UHI is difficult to quantify directly with observations, since the availability of long-term climatologic observational data in cities is limited. This is because official weather stations are preferably located in open rural or natural areas with the aim of obtaining a substantial spatial representativeness [13]. Consequently, long-term climatological observations to monitor urban heat are rarely available for cities. Other observational sources from urban areas such as amateur weather station data or field campaign data generally do not cover long periods, and the data often represent only small areas due to the high variability in temperature within the urban area setting [14,15]. To overcome this lack of observations, the UHI is often modeled using sophisticated atmospheric mesoscale models coupled to an urban canopy [16-19]. However, those models require large amounts of initial urban morphological data, which are often inaccurate and sometimes not available [20]. Another approach is to measure the UHI with remote sensing techniques [21,22]. However, correlations between remote-sensing-derived surface temperatures and air temperatures are weak, due to the absence of advection and flux divergence in the air volume [21]. In addition, the intervals of the revisiting times restrict a dynamical analysis of UHIs [22].

As an alternative approach, in this study, we diagnosed the daily maximum UHI by applying an empirical formula designed by Theeuwes et al. (2017) [20]. With this approach, we calculated urban minimum temperatures and compared them with rural minimum temperatures. The data needed in this equation consist of routine meteorological observations and morphological city characteristics. A novel concept is the application of this equation to determine the UHI for current and future climates in an urban agglomeration. As a test bed, we computed the UHI for the agglomeration of The Hague in the Netherlands (Figure 1). Previous research shows that cities of varying size in a maritime climate such as the Netherlands may experience severe heat stress [14]. This also holds for near-coastal cities like Rotterdam where nocturnal UHIs are up to $7^{\circ} \mathrm{C}$ during clear heat-wave days [23]. Molenaar et al. [24] estimated that the number of hours of experienced heat stress, here defined as the hours with physiologically equivalent temperatures above $23^{\circ} \mathrm{C}$, will double from the current average of about 250 hours per year to slightly more than 500 hours per year under the warmest Royal Netherlands Meteorological Institute (KNMI) climate scenario.

Also a novel concept, we investigated the impact of construction plans on the magnitude of the UHI. In the future, the Dutch government will face the challenge of building an additional one million residences before the year 2040 [25]. A substantial part of this new construction has to be developed within existing urban areas. This means that the population density will increase, which will apply pressure to the heat resiliency of cities. For instance, Steeneveld et al. [14] found a good correlation 
between the higher percentiles of UHI and population densities for Dutch cities of various sizes. Within the current research, we investigated the effect of different urban planning strategies on heat stress for current and future climate scenarios by creating heat maps with a resolution of $100 \mathrm{~m}$. The urban planning strategies refer to the redevelopment and the construction of additional residences within the urban neighborhoods. The construction differs between high-rise buildings and low- and mid-rise buildings. The choice has consequences for the urban morphological characteristics of an urban area, as vegetation fractions and sky-view factors are important parameters in determining the UHI. The aim of this study was to estimate urban night-time temperatures for current and future climate in order to obtain measures which reduce the UHI.

This paper is organized as follows: Section 2 summarizes the modeling approach and introduces the climate scenarios and urban planning strategies we explored. Section 3 presents the results we obtained. Finally, in Sections 4 and 5, we reflect on our modeling approach and outcomes, and we draw conclusions.

\section{Methods}

This section presents the followed research methodology, the utilized KNMI climate scenarios, and the study area.

\subsection{Study Area}

The Ministry of Infrastructure and Environment of the Netherlands was interested in the consequences of climate change and additional housing on heat stress in cities. The Hague was chosen, because it is located in a large urbanized area where there is a great demand for housing [25]. The study area (referring to rectangle in Figure 1A) includes the cities of The Hague, Delft, and Zoetermeer, as well as the green agricultural areas that surround these cities. These cities have 532,561, 102,253, and 124,695 inhabitants, respectively [26], spread over $98.12,24.06$, and $37.06 \mathrm{~km}^{2}$, respectively. Other cities were included in our study to allow for a reliable verification and to enable a robust statistical relationship between residence density and urban morphological characteristics (see Section 2.2). Taking into account the population of the smaller villages and hamlets, the agglomeration of The Hague accommodates about one million inhabitants. It is one of the most densely populated regions in the Netherlands. The study area has a population density of 1270 inhabitants per $\mathrm{km}^{2}$ [27].

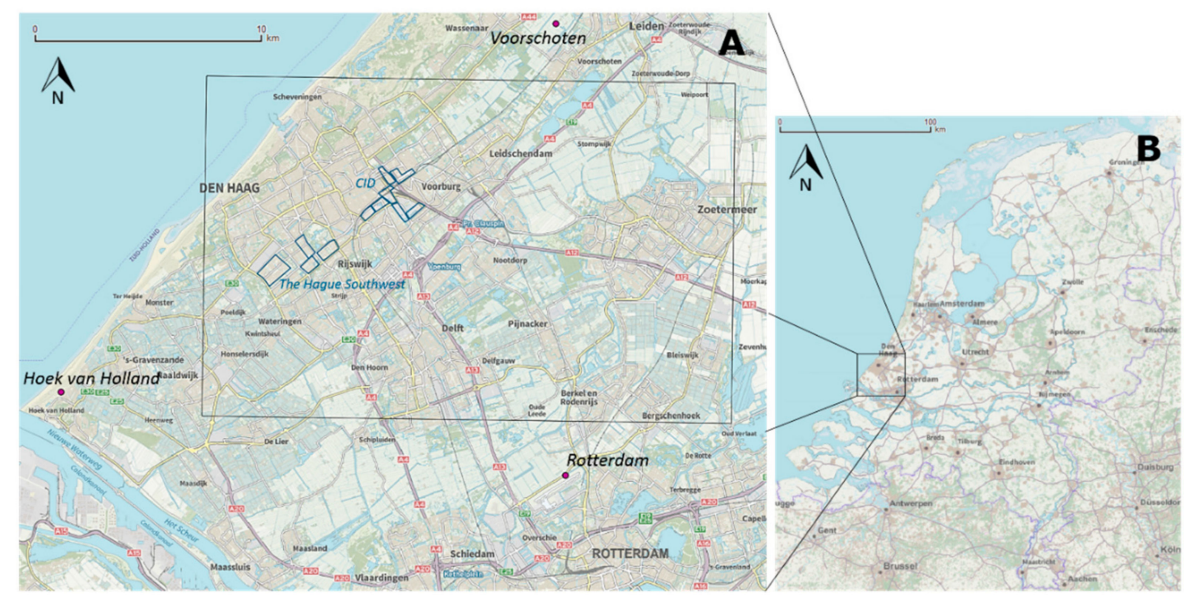

Figure 1. The agglomeration of The Hague (panel A) and an overview map of the Netherlands (panel B) [28]. The black rectangle in panel A indicates the study area for which the heat map was calculated. The three WMO stations are indicated in italics (Voorschoten, Hoek van Holland, and Rotterdam). Rotterdam acts as a rural reference station. The blue shapes in The Hague (Den Haag) represent the urban districts, Central Innovation District (CID), and The Hague Southwest, for which different urban planning strategies were evaluated for heat stress. 
The climatological conditions of these regions are characterized by the vicinity of the North Sea. The prevailing wind direction is from the southwest. The temperature distribution is rather mild with maximum and minimum temperatures of $21^{\circ} \mathrm{C}$ and $16^{\circ} \mathrm{C}$ in August. In January, the daily maximum and minimum temperatures amount to $6{ }^{\circ} \mathrm{C}$ and $3{ }^{\circ} \mathrm{C}$. The yearly precipitation measures $666 \mathrm{~mm}$, with the largest monthly precipitation in November.

\subsection{Diagnostic Equation to Compute Minimum Temperatures in Cities}

Urban heat islands and urban temperatures can be estimated looking at the combined effects of weather conditions and urban morphological characteristics. From these factors, a daily maximum urban heat island $\left(\mathrm{UHI}_{\max }\right)$ can be estimated using a diagnostic equation created by Theeuwes et al. (2017), henceforth referred as T17 [20] (Equation (1)).

$$
\begin{aligned}
& \text { urban morphology meteorology } \\
& \mathrm{UHI}_{\max }=\left(2-\mathrm{SVF}-\mathrm{f}_{\mathrm{veg}}\right) \sqrt[4]{\frac{\mathrm{S}^{\downarrow} \mathrm{DTR}}{\mathrm{U}}} .
\end{aligned}
$$

This equation was validated using observational data from 14 cities across northwestern Europe that vary in size. The equation appears to be robust. The $\mathrm{UHI}_{\max }$ expresses the maximum temperature difference between urban and rural environments on a given day in Equation (1). SVF denotes the sky-view factor and $f_{v e g}$ denotes the vegetation fraction of the urban area. $S \downarrow$ denotes the mean downward shortwave radiation $\left(\mathrm{K} \cdot \mathrm{ms}^{-1}\right)$, DTR denotes the diurnal temperature range $(\mathrm{K})$, and $U$ denotes the mean wind speed $\left(\mathrm{m} \cdot \mathrm{s}^{-1}\right)$ measured at a rural station nearby the city. The average measurement period for each of the meteorological parameters can be found in T17 [20]. The heat maps are computed on grid cells with a resolution of $100 \mathrm{~m}$. The SVF and vegetation fraction were determined using a source area of 500 by $500 \mathrm{~m}$ around the grid cell, which was designated to a $100 \mathrm{~m}$ resolution. The SVF originates from a 5-m-resolution dataset [29], derived from a digital elevation model based on airborne lidar measurements from aircraft measurements made in 2008 [30]. Upscaling from a 5-m to a 500-m resolution was performed by taking the median of street level SVF data points. The vegetation fraction dataset originates from a normalized difference vegetation index map (NDVI) [31].

The spatial contrast of the $\mathrm{UHI}_{\max }$ across the city is a good measure to estimate which parts of the city suffer more from heat stress. Nevertheless, when climate change is incorporated, the UHI max is not an adequate measure of heat stress anymore, since climate change is heating up the world regardless of whether an area is classified as rural or urban. Therefore, it is useful to make an evaluation based on the absolute values of urban temperatures, such as minimum temperatures $\left(\operatorname{Tn}_{\text {city }}\right)$, which can be computed as follows:

$$
\mathrm{Tn}_{\text {city }}=\mathrm{Tn}_{\text {rural }}+\mathrm{UHI}_{\max } \times 0.46 .
$$

When minimum temperatures are observed at the rural reference station, the UHI is typically substantially smaller than the $\mathrm{UHI}_{\max }$. On a typical cloudless day, the minimum rural temperature increases by $46 \%$ of the $\mathrm{UHI}_{\max }$ [3]. This fraction of the UHI $\max$ is also known as the UHI $\mathrm{UMIN}_{\mathrm{T}}$. The WMO station in Rotterdam acts as a rural reference station (provides $\mathrm{Tn}_{\text {rural }}$ in Equation (2)) (Figure 1A). Measurements from other nearby WMO stations were discarded, because they were located too close to the sea (Hoek van Holland) or were recently relocated (Voorschoten). In order to compute climatologies, we used the data from 15 summer half-years (1 April-30 September) covering the years 2002 to 2016 from the WMO station Rotterdam. Finally, we present heat maps showing the average number of nights per year that exceed the minimum temperature of $20^{\circ} \mathrm{C}$. This metric is consistent with ongoing climate adaption policies in the Netherlands [32]. These nights are often referred to as tropical nights. The heat maps were generated with the QGIS software [33]. 


\subsection{Future Climate Scenarios}

For future climate scenarios, the meteorological time series from the rural station Rotterdam during the period 2002-2016 were transformed into the projected climate of 2050. The Netherlands weather services (KNMI) developed four different scenarios to depict how the climate may evolve, namely the $\mathrm{G}_{\mathrm{L}}, \mathrm{G}_{\mathrm{H}}, \mathrm{W}_{\mathrm{L}}$, and $\mathrm{W}_{\mathrm{H}}$ scenarios. The scenarios differ in the estimated global temperature rise $(\mathrm{G}$ or $\mathrm{W})$ and the degree of change in air circulation patterns ( $\mathrm{L}$ and $\mathrm{H}$ suffix), all of which are schematically represented in Figure 2.

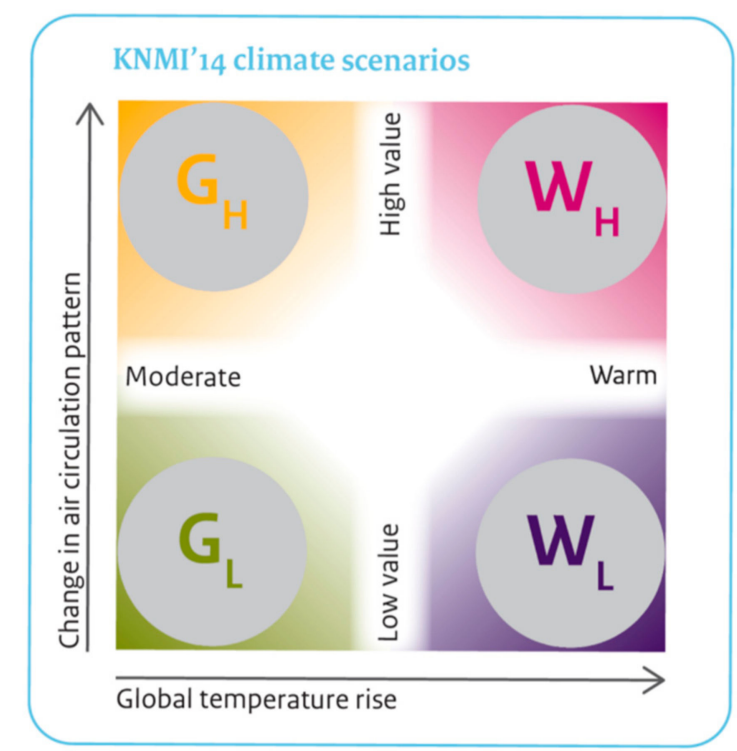

Figure 2. Four scenarios were used to calculate future heat stress. They differ in global temperature rise and change in air circulation pattern. Reproduced with permission from KNMI, Brochure KNMI'14 climate scenarios, 2015 [34].

These climate scenarios are based on the Intergovernmental Panel on Climate Change (IPCC) global climate model calculations, on global climate model EC-Earth results, and on a downscaling step within the regional climate model, Racmo [34]. All four scenarios have an equal chance of occurrence. As indicated in Figure 2, the scenarios differ in the degree of change in air circulation patterns and the global temperature rise. The differences in global temperature rise are due to different projections of greenhouse-gas emissions adopted from the emission scenarios from the IPCC [34]. The scenarios $\mathrm{G}_{\mathrm{L}}$ and $\mathrm{G}_{\mathrm{H}}$ match the lower end of the emission reduction scenarios (RCP4.5 and RCP6), and the scenarios $W_{L}$ and $W_{H}$ match the high-emission scenario (RCP8.5) which does not include specific climate mitigation [35,36]. Within all of the model simulations, a distinction can be made between models showing a large and small precipitation response [37]. Simulations with a large precipitation response foresee wet humid winters and dry summers, and are assigned to $\mathrm{H}$-scenarios. The change in precipitation response is linked to circulation change, and $\mathrm{H}$-scenarios show more frequent westerly circulation in the winter and domination of high pressure in the summer. In the summer, this means an increase in solar radiation and more easterly winds, which implies higher temperatures. This weather type also favors urban heat islands.

The scenarios provide monthly temperature increments for daily percentiles [38]. These increments were relative to the climate period of 1981-2010. There is already a climate signal in the time series (2002-2016) compared to this climate period, and this bias was subtracted from the results. Using the procedure of Molenaar et al. [24], these increments were interpolated for all of the days in a month. In this study, the transformation was performed on hourly values, because the time frame in which minimum temperatures were determined differs from the standard, i.e., from 8:00 a.m. universal 
coordinated time (UTC) to 8:00 a.m. UTC the next day. After the creation of a future hourly time series, a proper minimum temperature can be derived. As such, we use

$$
T^{f}(h)=T^{c}(h)+\Delta T(d)+\Delta H T D(h)-\overline{\Delta H T D(h)},
$$

where

$$
\Delta H T D(h)=\frac{\left(T^{c}(h)-T_{\min }^{c}\right)}{\left(T_{\max }^{c}-T_{\min }^{c}\right)} \times \Delta D T R .
$$

The symbols are defined by the following:

$T^{\mathcal{c}}(h)=$ hourly temperature current climate

$T_{\text {min }}^{c}=$ minimum daily temperature, 8:00 a.m. to 8:00 a.m. the next day

$T_{\max }^{c}=$ maximum daily temperature, 8:00 a.m. to 8:00 a.m. the next day

$T^{f}(h)=$ hourly temperature for future climate

$\Delta T(d)=$ daily temperature increment to future climate

$\triangle D T R=$ change in average diurnal temperature range to future climate

$\triangle H T D(h)=$ hourly temperature deviation

$\overline{\Delta H T D(h)}=24$-hour average bias of hourly temperature deviation

For a transformation to hourly values, the daily temperature increments, $\Delta T(d)$, were added to individual hours (see Equation (3)). This increment, $\Delta T(d)$, was the outcome of the procedure of Molenaar et al. [24]. A novel aspect is that the change in diurnal temperature range (DTR), $\triangle D T R$, between the future and current climate was also taken into account (Equations (3) and (4)). With Equation (3), a new dataset of minimum temperatures for 2050 can be directly calculated using the hourly temperature dataset of $T^{f}(h)$.

The UHI $\max$ also changes in a future climate (see Equation (1)). The scenarios generally show an increase in global radiation and generally show a decrease in DTR, which influences the UHI $\mathrm{Uax}_{\text {ax }}$. On the contrary, however, the H-scenarios $\left(\mathrm{G}_{\mathrm{H}}\right.$ and $\left.\mathrm{W}_{\mathrm{H}}\right)$ show a small increase in DTR for the warmest months of July and August. In all climate scenarios, these months show an increase in global radiation from $2 \%$ in the $G_{L}$ scenario to $7 \%$ in the $W_{H}$ scenario, as well as a change in DTR between $-3 \%$ in the $\mathrm{G}_{\mathrm{L}}$ scenario and $2 \%$ in the $\mathrm{W}_{\mathrm{H}}$ scenario. For the transformation in global radiation, we followed the method of Bakker [39]. The climate scenarios provided only monthly changes in global radiation. In our study, the change in radiation was distributed over all days without exceeding the maximum realistic daily radiation sum, which was set at $75 \%$ of the radiation at the top of the atmosphere [39]. Changes in wind speed were not considered, because they fell within the natural variation range [34]. Transformation numbers can

\subsection{Urban Planning Strategies}

The impact of the redevelopment and the construction of additional residences was evaluated for two urban districts. One district was a residential area consisting of low- and mid-rise buildings located in the southwestern part of The Hague, referred to as "The Hague Southwest" (Figure 3A). The other district was located near the center of The Hague and mainly consisted of a relatively old business area and newer high-rise commercial buildings. This area is scheduled for redevelopment, and is referred to as the Central Innovation District (CID) (Figure 3B). The densification of this district is much larger than that of The Hague Southwest, because of the larger building assignment.

The building assignments of the districts could either be achieved by building on currently green spaces or by replacing the existing low- and mid-rise buildings with high-rise buildings. This will either reduce the vegetation fraction or raise the SVF, which will consequently increase the UHI $\mathrm{Uax}_{\text {. }}$. This choice and the alternative of building residences in surrounding green corridors were examined using five distinct urban planning strategies shown in Table 1. 

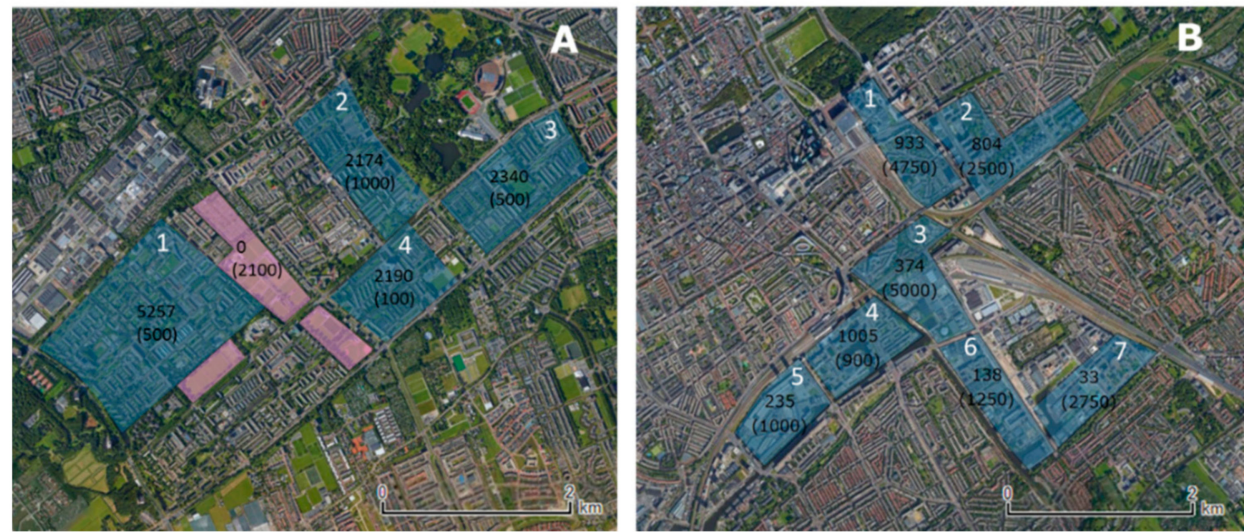

Figure 3. Theoretical building assignment for districts of The Hague Southwest (panel A) and the CID (panel B). The building assignment is indicated for different neighborhoods within brackets, and the number above the brackets indicates the current number of residences in the neighborhood. The pink areas in panel A indicate green corridors which were built using strategy $\mathrm{C}$. The white numbers label the different neighborhoods.

Table 1. Five urban planning strategies that complete the building assignments for The Hague Southwest and the Central Innovation District (CID). The enumeration starts with B, in accordance with the panels in Figures 8 and 10. Panel A in these figures represents the current housing.

\begin{tabular}{llll}
\hline \multicolumn{1}{c}{ The Hague Southwest } & CID (Central Innovation District) \\
\hline B. $\begin{array}{l}\text { Build on green corridors around the urban } \\
\text { neighborhoods with low- and mid-rise buildings. } \\
\text { Construct low- and mid-rise buildings on green } \\
\text { spaces within the urban neighborhoods. }\end{array}$ & B. & $\begin{array}{l}\text { Construct high-rise buildings whereby green } \\
\text { spaces are preserved as much as possible. }\end{array}$ \\
$\begin{array}{l}\text { Construct high-rise buildings within the urban } \\
\text { neighborhoods to preserve existing green spaces. }\end{array}$ & C. & $\begin{array}{l}\text { vegetation fraction is increased. } \\
\text { vegeby the }\end{array}$ \\
\hline
\end{tabular}

In this study, the building assignment was expressed as a change in the SVF and/or vegetation fraction in order to estimate the changes in the UHI (see Equation (1)). Hence, as a first step, we had to determine the numerical relationship among the density of the residences [27], the SVF, and the vegetation fraction $\left(f_{v e g}\right)$ for the current building volume of the agglomeration of The Hague. This is expressed as

$$
\text { Residences per } \mathrm{km}^{2}=-213( \pm 19) \mathrm{SVF}-200( \pm 30) \mathrm{f}_{\mathrm{veg}}+1.85( \pm 0.04)\left(\mathrm{SVF} \times \mathrm{f}_{\mathrm{veg}}\right)+22687
$$

Figure 4 shows the empirical relationship among the density of the residences, the SVF, and the $f_{v e g}$ in a three-dimensional (3D) plot. Herein, the SVF and the $f_{v e g}$ are denoted in percentages. The ranges used for this relationship vary between $52-99 \%$ and $11-93 \%$ for the SVF and the $\mathrm{f}_{\mathrm{veg}}$, respectively. For the CID, it was necessary to extrapolate to a minimum SVF of $22 \%$ and a vegetation fraction of $5 \%$ to meet the requirements of the high density of residences. Note that the population density does not currently occur in the agglomeration of The Hague. The UHI max equation (Equation (2)), however, was tested for highly urbanized areas [20]; thus, it can deal with the planned densification for the CID. The values used for the SVF, the $f_{v e g}$, and the density of residences for the five urban planning strategies can be found in Tables A1 and A2 in Appendix A. 


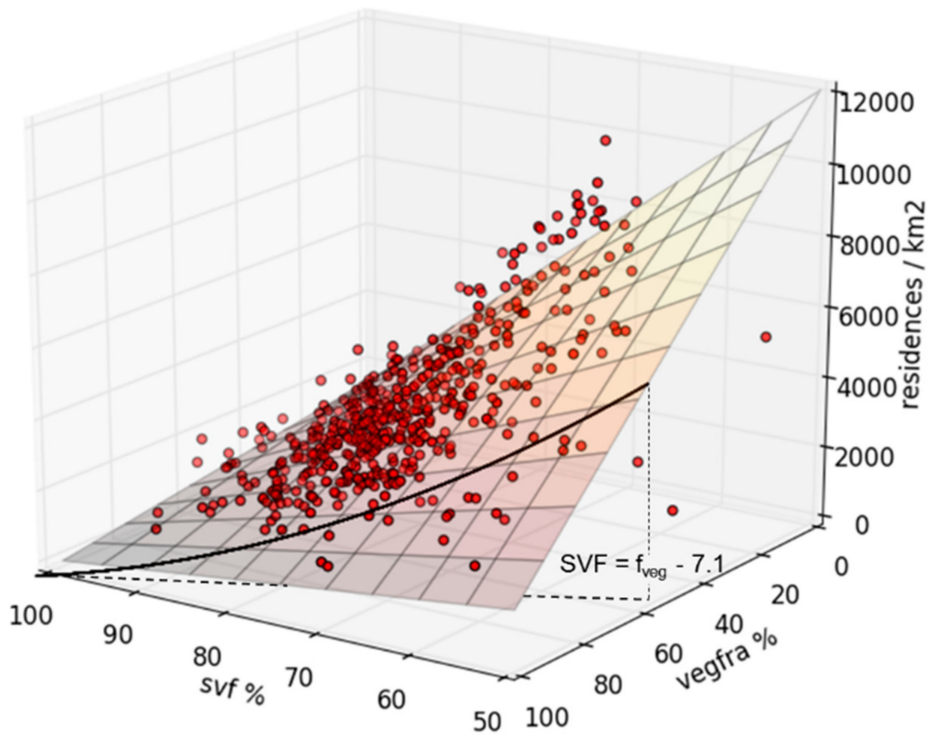

Figure 4. Empirical relationship among the density of the residences [27], the sky-view factor (SVF), and the vegetation fraction for the agglomeration of The Hague presented on a three-dimensional (3D) surface $\left(R^{2}=0.64\right)$. Areas with more than one-third non-residential buildings were removed from the analysis. Areas with a population density below 750 per $\mathrm{km}^{2}$ were also removed. The black line and the black dotted line indicate the equilibrium between the slopes of the vegetation fraction and the SVF. The grid resolution used is $500 \mathrm{~m}$.

\section{Results}

\subsection{Model Validation for the Agglomeration of The Hague}

The diagnostic equation for the UHI applied here (Equation (2)) was designed and tested using observational data from cities of variable sizes in northwestern Europe [20]. It was crucial to verify the results presented here with citizen weather stations in the agglomeration of The Hague. Firstly, minimum temperatures are a different metric from the maximum UHI used for verification by T17 [20]. Secondly, the retrieval and integration of morphological data and meteorological data were slightly different compared with the procedure of T17 [20]. Finally, spatial differences may occur because the area is bordered by the coast, where seasonality in sea-surface temperatures and the presence of a sea breeze may play a role.

A quality assessment of crowdsourced weather data is indispensable, because weather stations may have issues and are not always properly installed [40,41]. For the verification, we used data from citizen weather stations in the agglomeration of The Hague, and data were also obtained from the Weather Underground platform. We selected only Davis Vantage Pro and Oregon scientific stations, since they show small biases in the night [40]. This added up to nine stations in total. The time series from these stations comprised two years of data (2015-2016) restricted by the summer period (April-October). Minimum temperatures were discarded if more than two hourly values were missing (as in the analysis by Hopkinson et al. [42]). After evaluating this constraint, the minimum availability was $48 \%$ and the average availability was $78 \%$ for a single citizen station.

The citizen weather stations and the diagnostic equation were compared in a quantile-quantile plot in Figure 5A, and the bias and standard deviation of the stations grouped by percentile are shown in Figure 5B. Only the lower percentiles with low minimum temperatures had a substantial cold bias. It is expected that the lack of anthropogenic heat led to the underestimation in the diagnostic equation (Equation (2)). During cold weather in the spring, the anthropogenic heat source is larger than in the summer due to heating of buildings [43]. Furthermore, in the lowest and highest percentile, there seemed to be more variance in minimum temperatures of the citizen weather stations than in the modeled minimum temperatures of the diagnostic equation. The other percentiles showed good 
agreement between the model and the observations, with only slight cold biases, and supported the reliability of the equation.

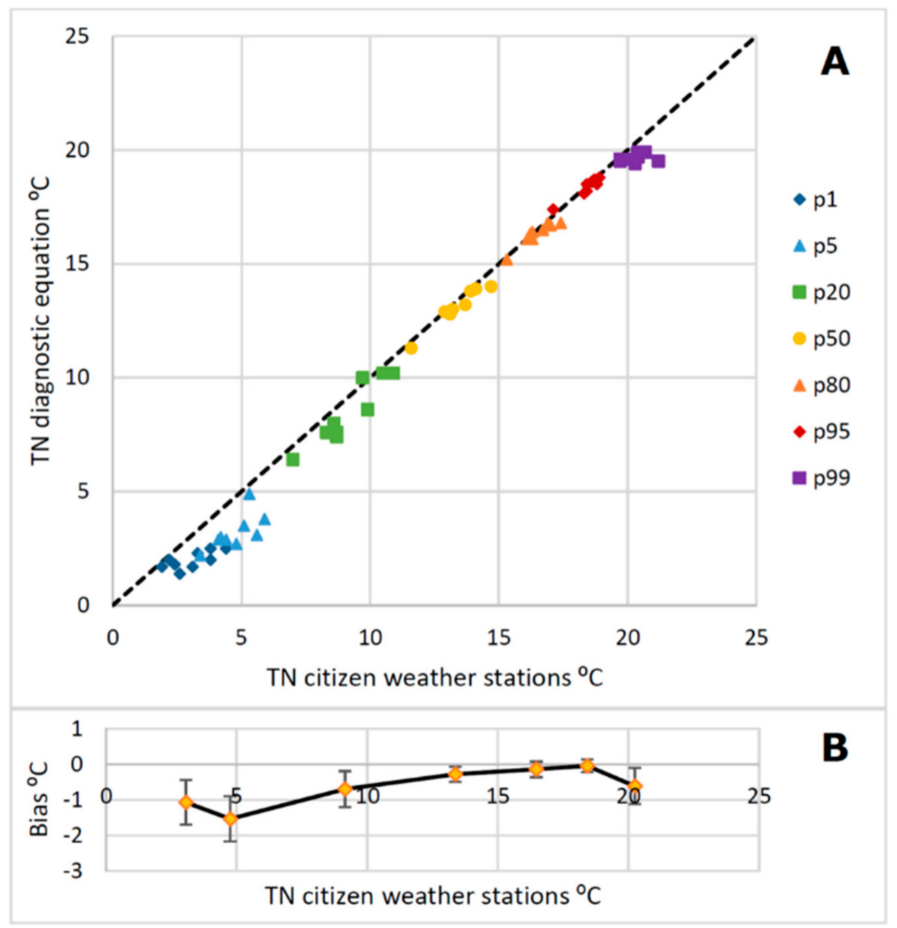

Figure 5. (A) Quantile-quantile plot for modeled and observed (Davis and Oregon citizen weather stations) night-time minimum temperatures for the years 2015-2016. (B) The bias between the data from these citizen weather stations and the diagnostic equation are presented as a function of temperature. Error bars indicate the standard deviation.

\subsection{Heat Stress for Current and Future Climate in 2050}

As a starting point, a heat map of the current climate was constructed for The Hague (Figure 6). Note that this heat map covered a smaller area than the study area displayed in Figure 2. In the current climate, tropical nights are not common. On average, rural areas experience 1.25 tropical nights per year, while the urbanized parts of The Hague face 3.5 to a maximum 4.5 tropical nights per year.

Note that, in rural areas, the number of tropical nights was distributed quite uniformly over the 15 years. During a few $(20 \%)$ of the years, there were no tropical nights and the warmest year in the series, 2006, had three tropical nights. The tropical nights typically occurred when weather conditions were governed by a warm humid cyclonic southerly flow with an upper level trough west of the European continent and approaching fronts, sometimes referred to as a Spanish plume [44]. These situations are unstable with high chances of thunderstorm and squall lines bringing in colder air masses; therefore, such situations do usually not last long. These situations prevent rural areas from developing a cool stable boundary layer at night. Urban areas may experience tropical nights particularly during relatively long warm episodes or heat waves, which is more often accompanied by an anticyclonic weather type. For the year 2006, a maximum of 14 tropical nights occurred in the center of The Hague. Six tropical nights occurred within a period of eight days. Note that a warm summer like 2006 is not unlikely in the current climate. The return time of such a summer is estimated at eight years [45]. 


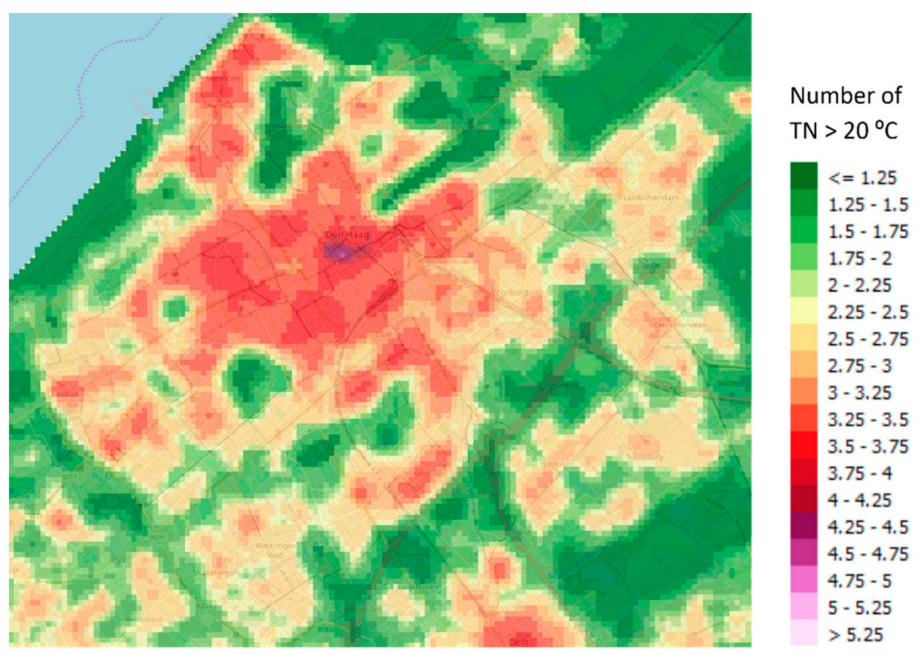

Figure 6. Modeled average number of nights per year above $20^{\circ} \mathrm{C}$ for the current climate (2002-2016) for The Hague.

Concerning the climate in 2050, we foresee that the number of tropical nights will increase substantially. Depending on the scenario, rural areas may experience 2.1-5.8 tropical nights per year, and the center of The Hague may experience 6.5-16 tropical nights per year (Figure 7). For the city, this means a three- to fourfold increase in tropical nights for the warmest $\mathrm{W}_{\mathrm{H}}$ scenario compared to the current climate. The observed warm year 2006 would fall in between the $\mathrm{W}_{\mathrm{L}}$ and the $\mathrm{W}_{\mathrm{H}}$ scenarios for an average year around 2050. The transformed year 2006 would lead to 15 tropical nights in rural areas and up to 32 tropical nights in the center of The Hague for the $\mathrm{W}_{\mathrm{H}}$ scenario.

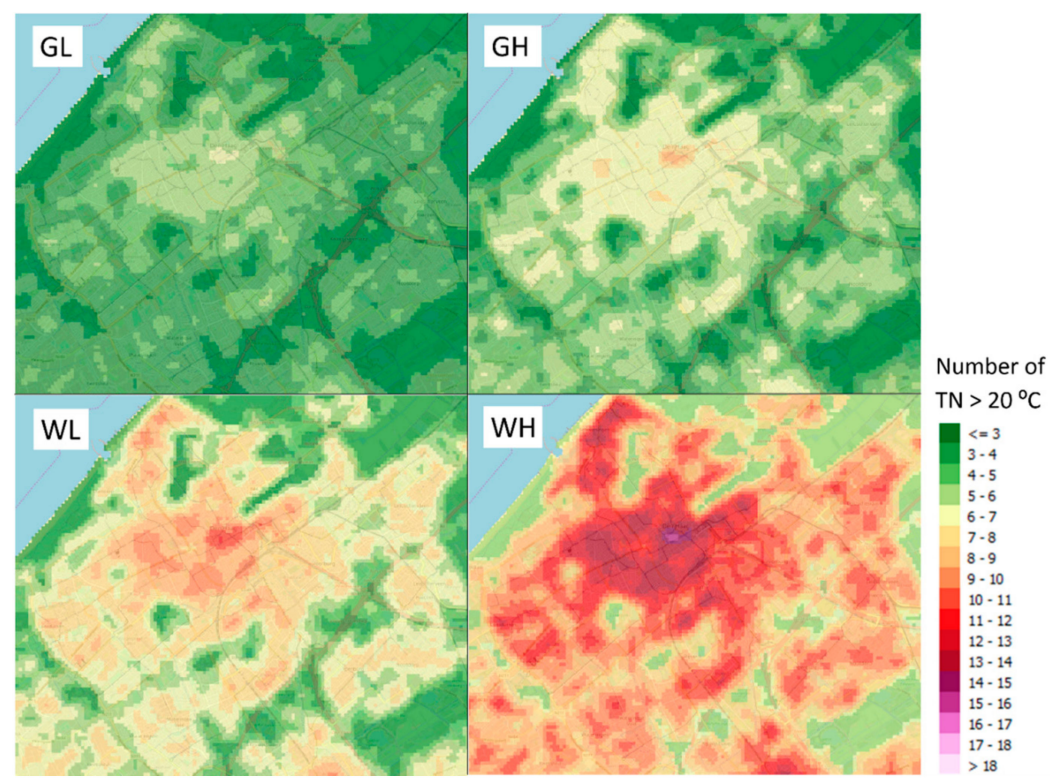

Figure 7. Modeled average number of nights per year above $20^{\circ} \mathrm{C}$ for the four Royal Netherlands Meteorological Institute (KNMI'14) scenarios representing the year 2050.

The absolute difference in tropical nights between rural and urban areas increases in the warmer scenarios, because more prevalent weather conditions will enable more tropical nights in cities in a warmer climate. Minimum temperatures simulated in cities of around $18{ }^{\circ} \mathrm{C}$ in the current climate will exceed $20^{\circ} \mathrm{C}$ in the $\mathrm{W}_{\mathrm{H}}$ scenario, and those nights will occur much more frequently than the tropical nights of today. Interestingly, the average UHI is likely to decrease a little for urban tropical nights in the future, because the more prevalent weather conditions are less related to strong UHIs. 
In any case, there will be very little change in the number of tropical nights for all future climate scenarios (less than $3 \%$ ). This is elaborated in the discussion.

\subsection{Urban Planning Strategies for The Hague Southwest}

For the urban district, The Hague Southwest, three urban planning strategies (abbreviated to strategies) were examined, and the impact on the number of tropical nights and $\mathrm{UHI}_{\max }$ was evaluated. The current climate does not indicate clear absolute differences in tropical nights between urban areas, due to the scarcity of these nights in low- and mid-rise urban areas. Therefore, the different strategies were shown for the future $\mathrm{W}_{\mathrm{H}}$ scenario only. The additional heat stress (measured in number of tropical nights per year) will be mostly scattered over the urban district in the strategy where new residences will be built on the currently green corridors around the neighborhoods (Figure 8A,B). The other strategies concentrate the heat stress particularly within the neighborhoods. The largest increase in the number of tropical nights takes place in neighborhood 2, which has the highest density of residences with the largest building assignment (Figure 3). For the hottest place in this district, the average number of tropical nights per year will increase from 3.1 to 3.5 in the current climate (not shown), and from 11 to 13 nights in the $W_{H}$ scenario shown in Figure $8 C, D$ (the mildest $G_{L}$ scenario shows an increase from 4.7 to $5.4-5.5$ tropical nights per year). Thus, the maximum expected numbers of tropical nights for this neighborhood in strategy $C$ and strategy $D$ are very similar. However, strategy $\mathrm{C}$ (construct low- and mid-rise buildings) shows larger patterns of these maxima than strategy $\mathrm{D}$ (construct high-rise buildings to preserve green spaces). Strategy $\mathrm{C}$ is moderately warmer than strategy $\mathrm{D}$ for the entire urban district, especially in neighborhood 2. This is best seen in the continuous scale of the 95th percentile of $\mathrm{UHI}_{\max }$ in Figure 9 for the current climate. The maximum increase in the 95th percentile of $\mathrm{UHI}_{\max }$ is $1.2^{\circ} \mathrm{C}$ for strategy $\mathrm{C}$ and $0.8^{\circ} \mathrm{C}$ for strategy $\mathrm{D}$, and remains nearly constant for the future scenarios. Note that these relative differences in the scenarios are also reflected in the expected minimum temperatures. In summary, the realization of high-rise buildings to preserve existing green spaces appears to be a better strategy than constructing low- and mid-rise buildings on existing green spaces for The Hague Southwest.
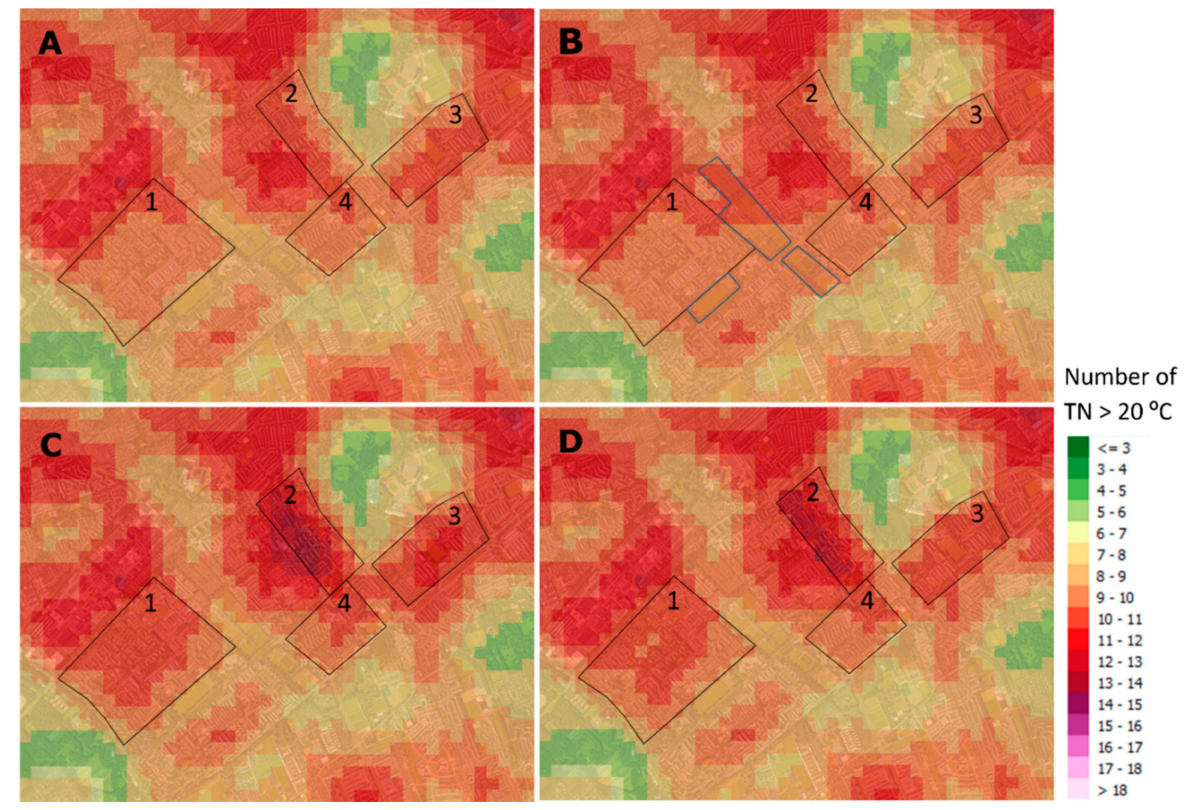

Figure 8. Modeled number of tropical nights per year for the $\mathrm{W}_{\mathrm{H}}$ climate scenario in 2050 for The Hague Southwest for: (A) current housing, (B) building on green corridors around the neighborhoods with low- and mid-rise buildings, (C) constructing low- and mid-rise buildings on green spaces within the urban neighborhoods, and (D) constructing high-rise buildings within the urban neighborhoods to preserve existing green spaces. 

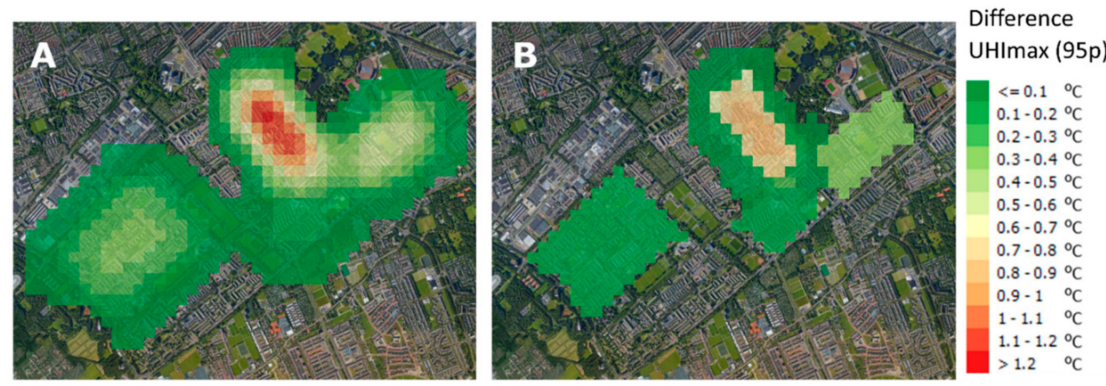

Figure 9. Difference in the modeled 95th percentile of $\mathrm{UHI}_{\max }$ between (A) strategy C (constructing low- and mid-rise buildings) and (B) strategy D (constructing high-rise buildings). Both are compared with the current housing for the current climate.

\subsection{Urban Planning Strategies for the CID}

For the CID (Central Innovation District), we looked at the frequency of tropical nights and $\mathrm{UHI}_{\max }$ to examine the effects of the urban planning strategies (Figures 10 and 11). In contrast to The Hague Southwest, the effect of the urban planning strategies is larger for the current climate, and therefore, is presented in Figure 10. The most urbanized neighborhoods 1 and 3 show the largest increase in tropical nights in both strategies, from 3.5 tropical nights per year up to more than five tropical nights per year in the current climate. The future climate scenarios foresee 8-15 tropical nights per year in the $G_{L}$ and $W_{H}$ scenarios, respectively. When compared to the district, The Hague Southwest, it is not clear which strategy is best. However, differences between the two strategies for the 95th percentile in $\mathrm{UHI}_{\max }$ reveal that the strategy where green spaces are preserved most (strategy $\mathrm{C}$ ) is the best choice (Figure 11). The neighborhoods 1, 2, 3, and 7 show mixed results, which is due to the small sizes of the areas. If the neighborhoods were larger, then strategy $C$ would result more clearly in less heat stress. In the Supplementary Materials the other climate scenarios are displayed for the urban planning strategies for CID and The Hague Southwest, the number of tropical nights for the warmest year 2006, and monthly transformation tables for temperature, DTR and global radiation from the current climate to the future climate in 2050.

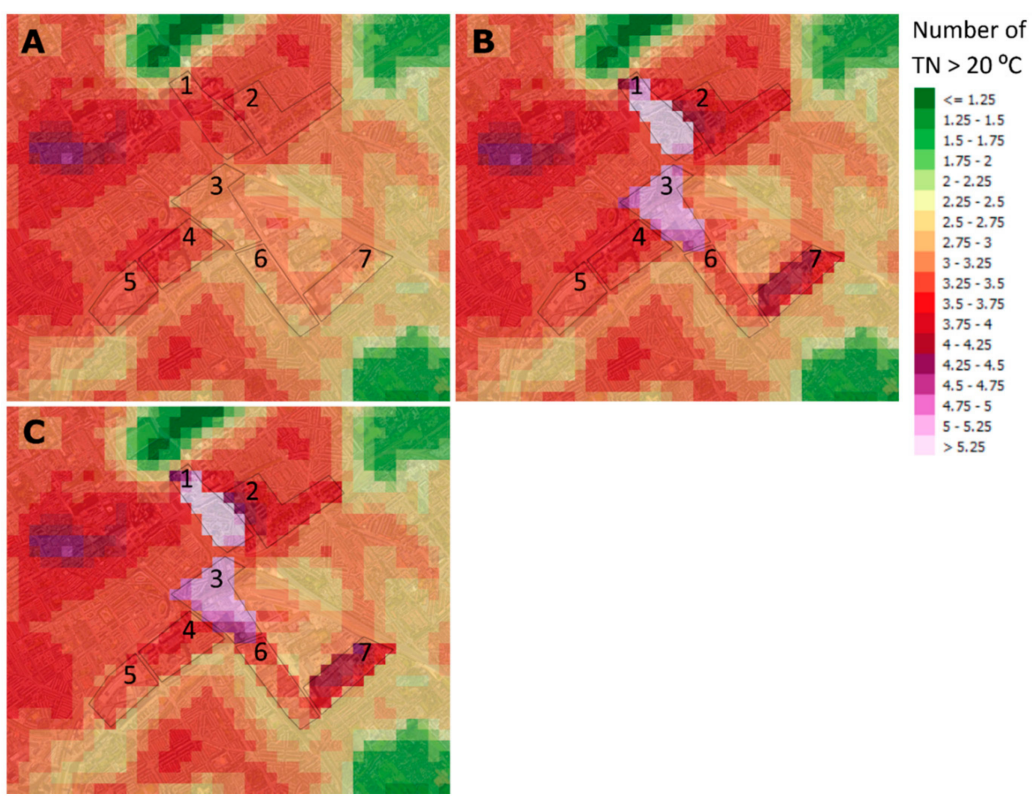

Figure 10. Modeled number of nights above $20^{\circ} \mathrm{C}$ per year for the CID in the current climate for (A) current housing, (B) constructing high-rise buildings whereby green spaces are preserved as much as possible, and (C) constructing high-rise buildings whereby the vegetation fraction is increased. 

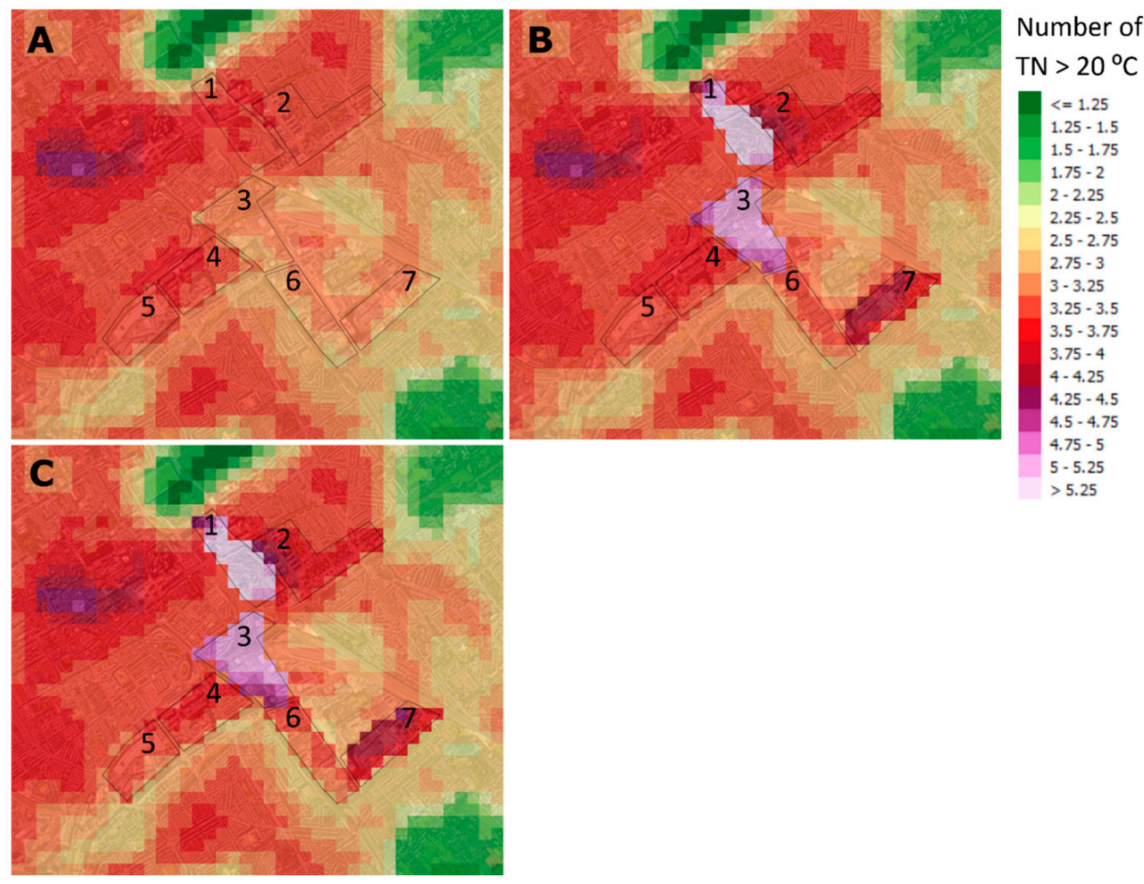

Figure 11. Difference in the modeled 95th percentile of the $\mathrm{UHI}_{\max }$ between strategy $\mathrm{B}$ and strategy $\mathrm{C}$ for the $\mathrm{W}_{\mathrm{H}}$ climate scenario.

\section{Discussion}

\subsection{Thresholds in Urban Planning Strategies}

In this paper, we studied the effects of different urban planning strategies on heat stress for current and future climates in the agglomeration of The Hague. It appears that preserving green spaces was clearly the best urban planning strategy in order to avoid heat stress for The Hague Southwest. The difference between the strategies for the CID was much smaller. An explanation for this difference appears when examining the statistical relationship among the density of residences, the SVF, and the vegetation fraction (Equation (5)). The larger the slope or partial derivative is in Equation (5), the more residences could be built per a certain decrease in SVF or decrease in vegetation fraction. Thus, the effectiveness of the strategy depends on the specific urban conditions. The vast majority of the data points in Figure 4 are positioned above the black line, which means that more residences could be built per percentage point decrease in the SVF than per percentage point decrease in the vegetation fraction. Note that a percentage point decrease in the SVF has the same effect on $\mathrm{UHI}_{\max }$ as a percentage point decrease in the vegetation fraction (Equation (1)). This means that, for the majority of neighborhoods, a decrease in the SVF due to high-rise buildings causes less heat stress than building low- and mid-rise buildings on green spaces.

$$
\mathrm{SVF}=\mathrm{f}_{\mathrm{veg}}-7.1 \text {. }
$$

The threshold which determines the favorable strategy can be derived from Equation (5) and is denoted in Equation (6). It is also represented as the dotted black line at the bottom of Figure 4 . Note that this relationship is specific for The Hague agglomeration and might alter slightly for other urban areas, even in the similar climates of other countries in northwestern Europe.

This threshold indicates that reducing the SVF by constructing high-rise buildings is a better measure, unless the SVF is considerably low and the vegetation fraction is high. This is relatively rare for the agglomeration of The Hague. The differences in effectiveness between the strategies can be attributed to the cross product in Equation (5), which appeared to be significant. The density of residences can be imagined roughly as a product of urban fraction (inverse of vegetation fraction) and 
height of the buildings (more or less correlated with the inverse of SVF). Two intermediate values in this product result in a substantial larger density of residences rather than a low and a high value for equal levels of heat stress.

\subsection{Applicability and Limitations of the UHI Diagnostic Equation}

Spatial variation in $\mathrm{UHI}_{\max }$ and night-time minimum temperatures within cities were investigated several times using multi-year observation data in cities. Montavez et al. [46] found that the urbanization of Granada in Spain resulted in increased night-time minimum temperatures predominantly in the city center. Eliasson [47] concluded that urban-park temperature differences were on the same order of magnitude as urban-rural temperature differences, which corresponds to large parks in The Hague. Heusinkveld et al. [23] found that spatial differences in vegetation cover are paramount in determining the spatial variation in UHI, and the correlation coefficients were best for an upwind fetch area of $700 \mathrm{~m}$. In the current study, the wind direction was not taken into account, and therefore, a smaller area of 500 by $500 \mathrm{~m}$ was an appropriate choice. When considering SVF, an aerial mean is used to relate the SVF to UHI to incorporate advection effects on air temperature, which was performed in studies such as those by Goh et al. [48] and Unger [49]. Similar to our study, Unger [49] extracted the SVF on a scale of 500 by $500 \mathrm{~m}$.

The verification of two years of crowdsourced city temperature data reveals that the diagnostic method used in this study does not indicate substantial biases in minimum temperatures in urban areas. This supports the use of the current diagnostic equation. Although the diagnostic equation is a physically meaningful equation with conservation of fundamental dimensions, not all potentially important contributing factors were taken into account. One can think of contributing factors such as anthropogenic heat, albedo, thermal admittance, which is related to the heat storage of buildings, distance to open water from a city's edge, and a vertical temperature gradient, as a measure for stability at the rural reference station. The latter two appeared to have less significance [20]. Caution is advised when applying the method to places that have large anthropogenic heat production like industrial areas or highly densely populated areas. Industrial areas were not sampled in the validation of T17 [20]. Anthropogenic heat can be included into the equation by adding it to the incoming solar radiation, or it can be added as a separate variable. When added to the incoming solar radiation, it has no substantial influence, apart from the cautioned areas with large anthropogenic heat production. Since the proximity to open water is not considered in the equation, the urban areas close to the sea have larger uncertainties for our study area. Open water is difficult to implement in a time-invariant $\mathrm{UHI}_{\max }$ equation, because the effect is strongly dependent on the season [50]. For albedo and thermal admittance, it is a challenge to retrieve reliable area-wide data on building properties. Albedo data can be straightforwardly retrieved from satellite observations, although a top view would over-represent roof albedo, which is less decisive on the street level than wall and street albedo [51].

A conversion factor of 0.46 was used to estimate the $\mathrm{UHI}_{\mathrm{TMIN}}$ from the UHI $\max$ (see Equation (2)). The ratio between $\mathrm{UHI}_{\max }$ and $\mathrm{UHI}_{\mathrm{TMIN}}$ (conversion factor) is probably not fixed for all the percentiles, as demonstrated in a crowdsourced data study conducted in the Netherlands [14], and for city weather stations in Rotterdam [23]. The last study reported $\mathrm{UHI}_{\max }$ to $\mathrm{UHI}_{\mathrm{TMIN}}$ ratios in the range of $0.63-0.87$ for the 95th percentile. However, it might be a safe choice to have a conservative conversion factor, since the rural reference station Rotterdam is affected by UHI mainly due to advection from Rotterdam and the airport itself [23]. Spatially, the conversion factor may change between areas with dominant narrow or wide street canyons [52].

\subsection{Climate-Change Projections on Heat Stress}

As demonstrated in Figure 7, the projected climate change could have a reasonably large-to-huge effect on heat stress levels. Regional climate models for Europe show similar outcomes. The high consistency in worsening health indices seem alarming for Europe [9]. Gasparrini et al. [53] and Huynen and Martens [54] found an increase in heat-related excess mortality for future climate 
scenarios. For the Netherlands, the population-attributable fraction of mortality is estimated to increase by $44-119 \%$, depending on the KNMI'14 climate scenarios [54]. Furthermore, mortality increases when heat waves are combined with air pollution [55]. Air pollution also increases with higher temperatures, due to the associated higher chemical reaction rates and elevated emissions of biogenic ozone precursors [56]. Nevertheless, the direct effect of elevated temperatures during heat waves seems to primarily be the effect of excess mortality [5,55].

Specific to the number of tropical nights, Fischer and Schär [9] showed a three- to fourfold increase in the number of tropical nights for France and Central Europe between 1961-1991 and 2021-2050. For downtown Paris, an increase from six to 35 tropical nights per year was estimated between current and future climate (A1B scenario 2071-2099) [57]. Apart from the different methodology used, these results are in line with our findings.

\subsection{Comparison of Urban Heat Island and Climate Scenario Contributions on Heat Stress}

Urban heat islands, as well as the projections of the climate scenarios for 2050, show significantly raised temperatures compared to rural areas in the current climate (see Figure 7). More specifically, rural areas in the $\mathrm{W}_{\mathrm{L}}$ and $\mathrm{W}_{\mathrm{H}}$ scenarios showed approximately the same number of tropical nights for the center of The Hague in the current climate. Nevertheless, climate change appears to create more significant heat stress than the imposed urbanization by the applied building assignments. This applies especially to The Hague Southwest. The neighborhoods 1 and 3 in the CID have large building assignments, and the increase in the number of tropical nights falls within the single climate-change effect of the $\mathrm{G}_{\mathrm{L}}$ and $\mathrm{G}_{\mathrm{H}}$ scenarios. In particular, the higher minimum temperatures showed a large increase in the climate scenarios. For the $5 \%$ warmest nights, an increase in night minima of $0.7^{\circ} \mathrm{C}$ is foreseen for the $\mathrm{G}_{\mathrm{L}}$ scenario, and up to $2.2{ }^{\circ} \mathrm{C}$ for the $\mathrm{W}_{\mathrm{H}}$ scenario $\left(1.2{ }^{\circ} \mathrm{C}\right.$ and $2.7^{\circ} \mathrm{C}$ compared to the reference climate period of 1981-2010). This climate-change effect is about the same for rural and urban areas, which is discussed in the next paragraph. In contrast, the impact of urban planning strategies is smaller, but still relevant. The largest relative temperature differences among the urban planning strategies were found in The Hague Southwest. The preserving green strategy led to a $42 \%$ lower increase in $\mathrm{UHI}_{\max }$ in the 95th percentile than the building on green spaces strategy, i.e., $0.33^{\circ} \mathrm{C}$ and $0.57^{\circ} \mathrm{C}$, respectively. For the CID, the building assignment was much larger, and the increased vegetation fraction strategy noted an increase of $1.09^{\circ} \mathrm{C}$ compared to $1.36^{\circ} \mathrm{C}$ for the preserving green strategy (difference of $20 \%$ ). Tropical nights in urban areas were generally related to a lower $\mathrm{UHI}_{\max }$ percentile, which corresponds to a lower $\mathrm{UHI}_{\max }$, and consequently, the numbers increased by $25 \%$.

The climate-change effect is nearly the same for rural and urban areas since the UHI will be very similar in the future climate. In the diagnostic equation for $\mathrm{UHI}_{\max }$ (Equation (1)), this is represented by an offset between a projected decrease in DTR and a projected increase in incoming short-wave radiation, except for the $\mathrm{W}_{\mathrm{L}}$ scenario. This scenario shows the largest decrease in DTR with an unchanged amount of sunshine. However, this results in a minor reduction in UHI by $2-3 \%$. In July and August, the UHI slightly increased (2-3\%) for the H-scenarios, according to the increase in DTR. Most other studies confirmed the small or non-significant average UHI changes for mid-latitude cities in western Europe for the future climate [58-60]. There are climate models even hinting at a decrease in $\mathrm{UHI}_{\max }$ and $\mathrm{UHI}_{\mathrm{TMIN}}$ due to larger projected precipitation deficits and associated drier soils in the summer time [57,59]. In such situations, rural temperatures increase, because less energy is used for evapotranspiration. Hamdi et al. [59] found that, for a coupled urban and regional climate model, the higher percentiles of $\mathrm{UHI}_{\mathrm{TMIN}}$ could decrease by $1{ }^{\circ} \mathrm{C}$. For our study area, the effect of soil dryness does not play a substantial role in the UHI, because the land is below sea level and ground water levels are controlled.

\section{Conclusions}

In this study, we investigated the effect of additional housing in constructed zones on heat stress, worked out using different urban planning strategies for the current and future climates for the city 
of The Hague (the Netherlands). The heat stress is expressed based on the frequency of tropical nights, where minimum temperatures are above $20^{\circ} \mathrm{C}$, and on the 95th percentile of the maximum daily urban heat island, $\mathrm{UHI}_{\max }$. The proposed additional housing was added near the city center and in a residential area in The Hague. The urban planning strategies were applied in delineated urban neighborhoods and differed in replacing low- and mid-rise buildings with high-rise buildings, or constructing buildings on vegetated areas. The temperature projection was computed using a validated diagnostic equation which combined weather data and urban morphological characteristics. The vegetation fraction appeared to be a more critical parameter than the sky-view factor, which was reduced by the tall buildings for the vast majority of urban configurations. This means that the combination of mid-rise and high-rise buildings with a preservation of vegetated areas was the best strategy. There is, however, an empirically determined optimum between vegetation fraction and sky-view factor. The most favorable green strategy mitigated the heat stress by $42 \%$ and $20 \%$ for the two urban districts tested.

In general, climate change will cause a larger increase in heat stress than the extra heat stress caused by the imposed urbanization. Only the largest imposed building assignments could compete with the colder climate scenarios. The most urbanized area of the city has on average 4.5 tropical nights per year. For this area, we found a range of 6.5-16 tropical nights per year for the coldest and warmest climate scenarios. For the warmest summer in the data series (year 2006), the number of tropical nights would increase from 14 in the current climate to 32 in the warmest climate scenario. The results were verified with a selection of high-quality citizen weather stations. The model results were in good agreement with observations and showed only a slight cold bias. The prescribed method based on a diagnostic equation is a fast and efficient way of determining climatologies in minimum temperatures, and it is directly applicable for other cities across northwestern Europe.

Supplementary Materials: The following are available online at http:/ /www.mdpi.com/2073-4433/9/9/353/s1, Figure S1: Modelled number of tropical nights per year for the year 2006, Figure S2: Modelled number of tropical nights per year for year 2006 transformed to the four KNMI'14 scenarios, Figure S3: Modelled average number of nights per year above $20^{\circ} \mathrm{C}$ for The Hague Southwest for the current climate, Figure S4: Modelled average number of nights per year above $20^{\circ} \mathrm{C}$ for The Hague Southwest for the $\mathrm{G}_{\mathrm{L}}$ climate scenario, Figure S5: Modelled average number of nights per year above $20^{\circ} \mathrm{C}$ for The Hague Southwest for the $\mathrm{G}_{\mathrm{H}}$ climate scenario, Figure S6: Modelled average number of nights per year above $20^{\circ} \mathrm{C}$ for The Hague Southwest for the $\mathrm{W}_{\mathrm{L}}$ climate scenario, Figure S7: Modelled number of nights above $20^{\circ} \mathrm{C}$ per year for the CID for the $\mathrm{G}_{\mathrm{L}}$ climate scenario, Figure S8: Modelled number of nights above $20^{\circ} \mathrm{C}$ per year for the $\mathrm{CID}$ for the $\mathrm{G}_{\mathrm{H}}$ climate scenario, Figure S9: Modelled number of nights above $20^{\circ} \mathrm{C}$ per year for the CID for the $\mathrm{W}_{\mathrm{H}}$ climate scenario, Table S1: Transformation table $\mathrm{G}_{\mathrm{L}}$ climate scenario from current climate to future climate in 2050, Table S2: Transformation table $\mathrm{G}_{\mathrm{H}}$ climate scenario from current climate to future climate in 2050, Table S3: Transformation table $\mathrm{W}_{\mathrm{L}}$ climate scenario from current climate to future climate in 2050, Table S4: Transformation table WH-scenario from current climate to future climate in 2050.

Author Contributions: Data curation, S.K.; Formal analysis, S.K.; Funding acquisition, R.R., G.-J.S. and A.M.G. K.T.; Investigation, S.K. and R.R.; Methodology, S.K., R.R. and A.M.G.K.T.; Project administration, G.-J.S.; Software, S.K.; Supervision, G.-J.S.; Validation, S.K.; Visualization, S.K.; Writing一original draft, S.K.; Writing一review \& editing, S.K., R.R., G.-J.S., A.A.M.H. and A.M.G.K.T.

Funding: This study was funded by the Ministry of Infrastructure and Environment.

Acknowledgments: The authors acknowledge feedback from Jan Willem Notenboom, Raymond Sluiter (KNMI Datalab), Rien Bout and Nieske Bisschop (Ministry of Infrastructure and Environment), Erik de Haan (Province of South Holland), and Arno Lammers (Municipality of The Hague). In addition, the authors acknowledge Andrea Pagani (KNMI Datalab) for the provision and feedback of the sky-view factor data. The authors acknowledge Weather Underground ${ }^{\circledR}$ for making the weather data available, which were used for verification, and acknowledge the weather enthusiasts for sharing their data to the platform of Weather Underground ${ }^{\circledR}$. We acknowledge Robin Palmer for language editing.

Conflicts of Interest: The authors declare no conflict of interest. 


\section{Appendix A}

Here, the values for the SVF and the vegetation fraction are presented, which were used for the urban planning strategies shown in Tables A1 and A2. According to strategies C and D, only one characteristic, the SVF or $\mathrm{f}_{\mathrm{veg}}$, was changed. The green corridor in strategy $\mathrm{B}$ has the urban characteristics of neighborhood 1, which allows it to meet the criteria of the building assignment.

For the CID strategy $C$, both the SVF and the $\mathrm{f}_{\mathrm{veg}}$ were changed for neighborhoods which became heavily urbanized in order to maintain realistic values. For instance, neighborhood 1 has urban characteristics similar to downtown Paris in strategy C [20].

Table A1. Values used for the sky-view factor (SVF) and the vegetation fraction for urban planning strategies in The Hague Southwest. In addition, the density of residences is indicated. Neighborhoods are displayed in Figure 3.

\begin{tabular}{|c|c|c|c|c|c|c|c|c|c|c|c|c|}
\hline \multirow{2}{*}{$\begin{array}{c}\text { Southwest } \\
\text { Neighborhood }\end{array}$} & \multicolumn{3}{|c|}{ A. Current Situation } & \multicolumn{3}{|c|}{$\begin{array}{l}\text { B. Building Green } \\
\text { Corridors }\end{array}$} & \multicolumn{3}{|c|}{$\begin{array}{c}\text { C. Building } \\
\text { Low-Mid-Rise }\end{array}$} & \multicolumn{3}{|c|}{$\begin{array}{l}\text { D. Preserve Existing } \\
\text { Green Spaces }\end{array}$} \\
\hline & $\operatorname{Res} / \mathbf{k m}^{2}$ & $f_{\text {veg }}$ & SVF & $\operatorname{Res} / \mathbf{k m}^{2}$ & $f_{v e g}$ & SVF & $\operatorname{Res} / \mathbf{k m}^{2}$ & $f_{\text {veg }}$ & SVF & $\operatorname{Res} / \mathbf{k m}^{2}$ & $f_{\text {veg }}$ & SVF \\
\hline 1 & 5344 & 0.51 & 0.73 & 5344 & 0.51 & 0.73 & 5852 & 0.43 & 0.73 & 5852 & 0.51 & 0.69 \\
\hline 2 & 5606 & 0.49 & 0.72 & 5606 & 0.49 & 0.72 & 8185 & 0.11 & 0.72 & 8185 & 0.39 & 0.58 \\
\hline 3 & 5305 & 0.48 & 0.70 & 5305 & 0.48 & 0.70 & 6439 & 0.32 & 0.70 & 6439 & 0.48 & 0.61 \\
\hline 4 & 6703 & 0.51 & 0.72 & 6703 & 0.51 & 0.72 & 7009 & 0.47 & 0.72 & 7009 & 0.51 & 0.69 \\
\hline 5 & 0 & $\mathrm{n} / \mathrm{a}$ & $\mathrm{n} / \mathrm{a}$ & 5344 & 0.73 & 0.51 & 0 & $\mathrm{n} / \mathrm{a}$ & $\mathrm{n} / \mathrm{a}$ & 0 & $\mathrm{n} / \mathrm{a}$ & $\mathrm{n} / \mathrm{a}$ \\
\hline
\end{tabular}

Table A2. Values used for the SVF and the vegetation fraction for the urban planning strategies in urban district CID. In addition, the residence density is indicated. Neighborhoods are displayed in Figure 3.

\begin{tabular}{ccccccccc}
\hline CID & A. Current Situation & \multicolumn{2}{c}{ B. Green Spaces Preserved } & \multicolumn{3}{c}{ C. Increased Vegetation Fraction } \\
\hline Neighborhood & $\mathbf{f}_{\text {veg }}$ & SVF & Res/km & $\mathbf{f}_{\text {veg }}$ & SVF & Res/km $\mathbf{~}^{2}$ & $\mathbf{f}_{\text {veg }}$ & SVF \\
\hline 1 & 0.20 & 0.71 & 17010 & 0.05 & 0.23 & 17010 & 0.06 & 0.22 \\
2 & 0.30 & 0.66 & 9811 & 0.13 & 0.55 & 9811 & 0.26 & 0.47 \\
3 & 0.21 & 0.87 & 15643 & 0.06 & 0.29 & 15643 & 0.10 & 0.26 \\
4 & 0.21 & 0.67 & 7706 & 0.17 & 0.64 & 7706 & 0.35 & 0.54 \\
5 & 0.08 & 0.80 & 5805 & 0.08 & 0.77 & 5805 & 0.47 & 0.60 \\
6 & 0.15 & 0.86 & 5907 & 0.15 & 0.74 & 5907 & 0.46 & 0.60 \\
7 & 0.19 & 0.82 & 11919 & 0.09 & 0.46 & 11919 & 0.19 & 0.39 \\
\hline
\end{tabular}

\section{References}

1. Intergovernmental Panel on Climate Change (IPCC). Managing the Risks of Extreme Events and Disasters to Advance Climate Change Adaptation. In A Special Report of Working Groups I and II of the Intergovernmental Panel on Climate Change; Field, C.B., Baros, V., Stocker, T.F., Qin, D., Dokken, D.J., Ebi, K.L., Mastrandrea, M.D., Mach, K.J., Plattner, G.-K., Allen, S.K., et al., Eds.; Cambridge University Press: Cambridge, UK; New York, NY, USA, 2012; p. 582. ISBN 978-1-107-02506-6.

2. Intergovernmental Panel on Climate Change (IPCC). Annex I: Atlas of Global and Regional Climate Projections. In Climate Change 2013: The Physical Science Basis. Contribution of Working Group I to the Fifth Assessment Report of the Intergovernmental Panel on Climate Change; Stocker, T.F., Qin, D., Plattner, G.-K., Tignor, M., Allen, S.K., Boschung, J., Nauels, A., Xia, Y., Bex, V., Midgley, P.M., Eds.; Cambridge University Press: Cambridge, UK; New York, NY, USA, 2013.

3. Oke, T.R. The energetic basis of the urban heat island. Q. J. R. Meteorol. Soc. 1982, 108, 1-24. [CrossRef]

4. Clarke, J.F. Some effects of the urban structure on heat mortality. Environ. Res. 1971, 5, 93-104. [CrossRef]

5. Basu, R. High ambient temperature and mortality: A review of epidemiologic studies from 2001 to 2008. Environ. Health 2009, 8, 1-40. [CrossRef] [PubMed]

6. Aida, M. Urban albedo as a function of the urban structure-A model experiment. Boundary-Layer Meteorol. 1982, 23, 405-413. [CrossRef] 
7. Holmer, B. A simple operative method for determination of sky view factors in complex urban canyons from fisheye photographs. Meteorol. Z. 1992, 1, 236-239. [CrossRef]

8. Allen, L.; Lindberg, F.; Grimmond, C.S.B. Global to city scale urban anthropogenic heat flux: Model and variability. Int. J. Climatol. 2011, 31, 1990-2005. [CrossRef]

9. Fischer, E.M.; Schär, C. Consistent geographical patterns of changes in high-impact European heatwaves. Nat. Geosci. 2010, 3, 398-403. [CrossRef]

10. Fouillet, A.; Rey, G.; Laurent, F.; Pavillon, G.; Bellec, S.; Ghihenneuc-Jouyaux, C.; Hémon, D. Excess mortality related to the August 2003 heat wave in France. Int. Arch. Occup. Environ. 2006, 80, 16-24. [CrossRef] [PubMed]

11. Joe, L.; Hoshiko, S.; Dobraca, D.; Jackson, R.; Smorodinsky, S.; Smith, D.; Harnly, M. Mortality during a Large-Scale Heat Wave by Place, Demographic Group, Internal and External Causes of Death, and Building Climate Zone. Int. J. Environ. Res. Public Health 2016, 13, 299. [CrossRef] [PubMed]

12. Garssen, J.; Harmsen, C.; de Beer, J. The effect of the summer 2003 heat wave on mortality in the Netherlands. Eurosurveillance 2005, 10, 165-167. [CrossRef] [PubMed]

13. WMO. Guide to Meteorological Instruments and Methods of Observation. 2014 edition WMO-No. 8. Available online: https:/ /library.wmo.int/opac/doc_num.php?explnum_id=4147 (accessed on 9 May 2018).

14. Steeneveld, G.J.; Koopmans, S.; Heusinkveld, B.G.; van Hove, L.W.A.; Holtslag, A.A.M. Quantifying urban heat island effects and human comfort for cities of variable size and urban morphology in the Netherlands. J. Geophys. Res. 2011, 116. [CrossRef]

15. Brandsma, T.; Wolters, D. Measurement and Statistical Modelling of the Urban Heat Island of the City of Utrecht (The Netherlands). J. Appl. Meteorol. Climatol. 2012, 51, 1046-1060. [CrossRef]

16. Chen, F.; Kusaka, H.; Bornstein, R.; Ching, J.; Grimmond, C.S.B.; Grossman-Clarke, S.; Loridan, T.; Manning, K.W.; Martilli, A.; Miao, S.; et al. The integrated WRF/urban modelling system: Development, evaluation, and applications to urban environmental problems. Int. J. Climatol. 2011, 31, 273-288. [CrossRef]

17. Salamanca, F.; Martilli, A.; Tewari, M.; Chen, F. A study of the urban boundary layer using different urban parameterizations and high-resolution urban canopy parameters with WRF. J. Appl. Meteorol. Climatol. 2011, 50, 1107-1128. [CrossRef]

18. Kusaka, H.; Kondo, H.; Kikega, Y.; Kimura, F. A simple single-layer urban canopy model for atmospheric models: Comparison with multi-layer and slab models. Bound. Layer Meteorol. 2001, 101, 329-358. [CrossRef]

19. Ronda, R.J.; Steeneveld, G.J.; Heusinkveld, B.G.; Attema, J.J.; Holtslag, A.A.M. Urban finescale forecasting reveals weather conditions with unprecedented detail. Bull. Am. Meteorol. Soc. 2017, 98, 2675-2688. [CrossRef]

20. Theeuwes, N.; Steeneveld, G.J.; Ronda, R.J.; Holtslag, A.A.M. A diagnostic equation for the daily maximum urban heat island effect for cities in Northwestern Europe. Int. J. Climatol. 2017, 37, 443-457. [CrossRef]

21. Roth, M.; Oke, T.R.; Emery, W.J. Satellite-derived urban heat islands from three coastal cities and the utilization of such data in urban climatology. Int. J. Remote Sens. 1989, 10, 1699-1720. [CrossRef]

22. Yuan, F.; Bauer, M.E. Comparison of impervious surface area and normalized difference vegetation index as indicators of surface urban heat island effects in Landsat imagery. Remote Sens. Environ. 2007, 107, 375-386. [CrossRef]

23. Heusinkveld, B.G.; Steeneveld, G.J.; van Hove, L.W.A.; Jacobs, C.M.J.; Holtslag, A.A.M. Spatial variability of the Rotterdam urban heat island as influenced by urban land use. J. Geophys. Res. Atmos. 2014, 119, 677-692. [CrossRef]

24. Molenaar, R.E.; Heusinkveld, B.G.; Steeneveld, G.J. Projection of rural and urban human thermal comfort in The Netherlands for 2050. Int. J. Climatol. 2016, 36, 1708-1723. [CrossRef]

25. EIB, Investeren in Nederland. Available online: https://www.eib.nl/pdf/investeren_in_nederland.pdf (accessed on 12 June 2015). (In Dutch)

26. CBS (Centraal Bureau voor de Statistiek) StatLine. Bevolking; Geslacht, Leeftijd, Regio. Available online: https: / / opendata.cbs.nl/statline / portal.html?_la=nl\&_catalog=CBS\&tableId=03759ned\&_theme=299 (accessed on 7 August 2018). (In Dutch)

27. CBS (Centraal Bureau voor de Statistiek) Kaart van 100 Meter bij 100 Meter Met Statistieken. Available online: https://www.cbs.nl/nl-nl/dossier/nederland-regionaal/geografische\%20data/kaart-van-100meter-bij-100-meter-met-statistieken (accessed on 8 May 2018). (In Dutch) 
28. OpenTopo Achtergrondkaart, Retrieved via PDOK-Services Plug-in in QGIS. (PDOK are the Dutch Public Geo Services). Available online: http:/ / pdokviewer.pdok.nl (accessed on 8 May 2018).

29. KNMI. Sky View Factor of the Netherlands. Available online: https://data.knmi.nl/datasets/sky_view_ factor_netherlands /1.0?q=sky+view (accessed on 26 February 2018).

30. AHN. Actueel hoogtebestand Nederland. Version 2. Available online: www.ahn.nl (accessed on 1 April 2012). (In Dutch)

31. Attema, J.J.; Heusinkveld, B.G.; Ronda, R.J.; Steeneveld, G.J.; Holtslag, A.A.M. Summer in the city: Forecasting and mapping human thermal comfort in urban areas. In Proceedings of the IEEE 11th International Conference on e-Science, Munich, Germany, 31 August-4 September 2015.

32. Climate Adaptation Services. Climate Impact Atlas. Available online: www.klimaateffectatlas.nl/en (accessed on 4 August 2018).

33. QGIS Development Team. QGIS Geographic Information System. Open Source Geospatial Foundation Project. Available online: https:/ / qgis.org/en/site/ (accessed on 31 August 2018).

34. Klein Tank, A.; Beersma, J.; Bessembinder, B.; van den Hurk, B.; Lenderink, G. KNMI'14 Climate Scenarios for the Netherlands, KNMI Publication: Brochure KNMI'14 Climate Scenarios; KNMI: De Bilt, The Netherlands, 2015; p. 34. Available online: http://www.klimaatscenarios.nl/brochures/images/Brochure_KNMI14_EN_2015. pdf (accessed on 1 July 2015).

35. Riahi, K.; Rao, S.; Krey, V.; Cho, C.; Chirkov, V.; Fischer, G.; Kindermann, G.; Nakicenovic, N.; Rafaj, P. RCP 8.5-A scenario of comparatively high greenhouse gas emissions. Clim. Chang. 2011, 109, 33-57. [CrossRef]

36. Cubasch, U.; Wuebbles, D.; Chen, D.; Facchini, M.C.; Frame, D.; Mahowald, N.; Winther, J.G. Introduction. In Climate Change 2013: The Physical Science Basis. Contribution of Working Group I to the Fifth Assessment Report of the Intergovernmental Panel on Climate Change; Cambridge University Press: Cambridge, UK; New York, NY, USA, 2013.

37. Van den Hurk, B.; Siegmund, P.; Klein Tank, A. KNMI'14: Climate Change Scenarios for the 21st Century-A Netherlands Perspective; Royal Netherlands Meteorological Institute (KNMI): De Bilt, The Netherlands, 2014. Available online: http:/ / bibliotheek.knmi.nl/knmipubWR/WR2014-01.pdf (accessed on 26 May 2014).

38. KNMI, Toelichting Transformatie Tijdreeksen. Available online: http://www.klimaatscenarios.nl/ toekomstig_weer/transformatie/Toelichting_TP.pdf (accessed on 6 October 2015). (In Dutch)

39. Bakker, A. Time Series Transformation Tool Version 3.1: Description of the Program to Generate Time Series Consistent with the KNMI'14 Climate Scenarios; Technical Report; KNMI: De Bilt, The Netherlands; p. 40. Available online: http:/ / bibliotheek.knmi.nl/knmipubTR/TR349.pdf (accessed on 17 November 2015).

40. Bell, S.; Cornford, D.; Bastin, L. How good are citizen weather stations? Addressing a biased opinion. Weather 2015, 70, 75-84. [CrossRef]

41. Meier, F.; Fenner, D.; Grassmann, T.; Otto, M.; Scherer, D. Crowdsourcing air temperature from citizen weather stations for urban climate research. Urban Clim. 2017, 19, 130-191. [CrossRef]

42. Hopkinson, R.F.; McKenney, D.W.; Milewska, E.J.; Hutchinson, M.F.; Papadopol, P.; Vincent, L.A. Impact of Aligning Climatological Day on Gridding Daily Maximum-Minimum Temperature and Precipitation over Canada. J. Appl. Meteorol. Climatol. 2011, 50, 1654-1665. [CrossRef]

43. CBS (Centraal Bureau voor de Statistiek) Statline. Aardgas; Aanbod en Verbruik. Available online: https: / / opendata.cbs.nl/statline / portal.html?_la=nl\&_catalog=CBS\&tableId=00372\&_theme=200 (accessed on 7 August 2018). (In Dutch)

44. Hamid, K. Investigation of the passage of a derecho in Belgium. Atmos. Res. 2012, 107, 86-105. [CrossRef]

45. KNMI, Warme en Zonnige Zomer 2006. Available online: https://www.knmi.nl/over-het-knmi/nieuws / warme-en-zonnige-zomer-2006 (accessed on 31 August 2006). (In Dutch)

46. Montavez, J.P.; Rodriguez, A.; Jiménez, J.I. A study of the urban heat island of Granada. Int. J. Climatol. 2000, 20, 899-911. [CrossRef]

47. Eliasson, I. Urban nocturnal temperatures, street geometry and land use. Atmos. Environ. 1996, 30, 379-392. [CrossRef]

48. Goh, K.C.; Chang, H.C. The relationship between height to width ratios and the heat island intensity at 22:00 h for Singapore. Int. J. Climatol. 1999, 19, 1011-1023. [CrossRef]

49. Unger, J. Intra-urban relationship between surface geometry and urban heat island: Review and new approach. Clim. Res. 2004, 27, 253-264. [CrossRef] 
50. Theeuwes, N.; Solcerova, A.; Steeneveld, G.J. Modelling the influence of open water surfaces on the summertime temperature and thermal comfort in the city. J. Geophys. Res. Atmos. 2013, 118, 8881-8896. [CrossRef]

51. Hamdi, R.; Schayes, B. Sensitivity study of the urban heat island intensity to urban characteristics. Int. J. Climatol. 2008, 28, 973-982. [CrossRef]

52. Theeuwes, N.; Steeneveld, G.J.; Ronda, R.J.; Heusinkveld, B.G.; van Hove, L.W.A.; Holtslag, A.A.M. Seasonal dependence of the urban heat island on the street canyon aspect ratio. Q. J. R. Meteorol. 2014, 118, 8881-8896.

53. Gasparrini, A.; Guo, Y.; Sera, F.; Vicedo-Cabrera, A.M.; Huber, V.; Tong, S.; Coelho, M.S.Z.; Saldiva, P.H.N.; Lavigne, E.; Correa, P.M.; et al. Projections of temperature-related excess mortality under climate change scenarios. Lancet. Planet. Health 2017, 1, e360-e367. [CrossRef]

54. Huynen, M.T.E.; Martens, P. Climate change effects on heat- and cold-related mortality in the Netherlands: A scenario-based integrated environmental health impact assessment. Int. J. Environ. Res. Public Health 2015, 12, 13295-13320. [CrossRef] [PubMed]

55. Analitis, A.; Michelozzi, P.; D’Ippoliti, D.; de'Donato, F.; Menne, B.; Matthies, F.; Atkinson, R.W.; Iñiguez, C.; Basagaña, X.; Schneider, A.; et al. Effects of heat waves on mortality: Effect modification and confounding by air pollutants. Epidemiology 2014, 25, 15-22. [CrossRef] [PubMed]

56. Athanassiadou, M.; Baker, J.; Carruthers, D.; Collins, W.; Girnary, S.; Hassel, D.; Hort, M.; Johnson, C.; Johnson, K.; Jones, R.; et al. An assessment of the impact of climate change on air quality at two UK sites. Atmos. Environ. 2010, 44, 1877-1886. [CrossRef]

57. Lemonsu, A.; Kounkou-Arnoud, R.; Desplat, J.; Salagnac, J.-L.; Masson, V. Evolution of the Parisian urban climate under a global changing climate. Clim. Chang. 2013, 116, 679-692. [CrossRef]

58. McCarthy, M.P.; Best, M.J.; Betts, R.A. Climate change in cities due to global warming and urban effects. J. Geophys. Res. 2010, 37. [CrossRef]

59. Hamdi, R.; van de Vyver, H.; de Troch, R.; Termonia, P. Assessment of three dynamical urban climate downscaling methods: Brussels's future urban heat island under an A1B emission scenario. Int. J. Climatol. 2014, 34, 978-999. [CrossRef]

60. Grossman-Clarke, A.; Schubert, S.; Fenner, D. Urban effects on summertime air temperature in Germany under climate change. Int. J. Climatol. 2017, 37, 905-917. [CrossRef] 